\title{
Triglyceride-glucose index (TyG index) is a predictor of incident colorectal cancer: a population-based longitudinal study
}

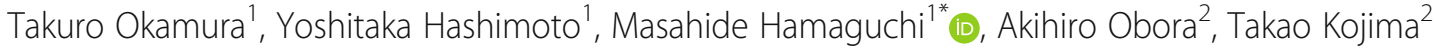 \\ and Michiaki Fukui ${ }^{1}$
}

\begin{abstract}
Background: Colorectal cancer (CRC), which is related with insulin resistance, is a one of the most common cancers. Triglyceride-glucose index (TyG index) was made for a marker of insulin resistance. We conducted the investigation of association between TyG index and incident CRC.

Methods: We examined the affect of TyG index on incident CRC in this historical cohort study of 27,944 (16,454 men and 11,490 women) participants. TyG index was calculated as In [fasting triglycerides (mg/dL) $\times$ fasting plasma glucose $(\mathrm{mg} / \mathrm{dL}) / 2$ ]. The impact of TyG index on incident CRC was investigated using Cox proportional hazard models, adjusting for sex, age, body mass index, smoking status, alcohol consumption, exercise, systolic blood pressure and creatinine. The covariate-adjusted receiver operating characteristic (ROC) curve calculated the area under the curve (AUC) and cut-off value of TyG index for the incidence of CRC.
\end{abstract}

Results: During the median 4.4-year follow-up, 116 participants were diagnosed as CRC. The cumulative incidence rate of CRC were $0.4 \%$. In Cox proportional hazard model, the HRs of TyG index were 1.38 (95\% Confidence interval $(\mathrm{Cl}), 1.00-1.91, p=0.049)$ after adjusting for covariates. In the covariate-adjusted ROC curve analysis, the cut-off value of TyG index for incident CRC was 8.272 (AUC 0.687 (95\%Cl, 0.637-737, sensitivity $=0.620$, specificity $=0.668, p<0.001$ )).

Conclusions: TyG index can predict the onset of CRC. For early detection of CRC, we should encourage people with high TyG index to undergo screening for CRC.

Keywords: Cohort study, Colorectal cancer, TyG index, Insulin resistance, Epidemiology

\section{Background}

Colorectal cancer $(\mathrm{CRC})$ is the third leading cause of the most common cancers next to lung and breast cancer in the world [1]. The most efficient strategies in reducing incident CRC are identification of patients with high-risk for CRC and performing colonoscopy.

\footnotetext{
* Correspondence: mhama@koto.kpu-m.ac.jp

'Department of Endocrinology and Metabolism, Kyoto Prefectural University of Medicine, Graduate School of Medical Science, 465, Kajii-cho, Kawaramachi-Hirokoji, Kamigyo-ku, Kyoto 602-8566, Japan

Full list of author information is available at the end of the article
}

Metabolic syndrome, i.e. obesity, impaired glucose tolerance, hypertension and dyslipidemia, has been reported to be associated with risk of CRC by several studies [2-6]. Particularly, insulin resistance is associated with hyperinsulinemia [7, 8], increased levels of insulinlike growth factors (IGF) $[9,10]$, and alterations in necrosis factor (NF) $-\kappa B$ [11] and peroxisome proliferatoractivated receptor gamma (PPAR $\gamma$ ) signaling [12], which plays a key role in the pathogenesis of CRC [13-15].

Triglyceride-glucose index (TyG index) was made for a marker of insulin resistance, and calculated with fasting plasma glucose and triglycerides [16, 17]. .In

(c) The Author(s). 2020 Open Access This article is licensed under a Creative Commons Attribution 4.0 International License, which permits use, sharing, adaptation, distribution and reproduction in any medium or format, as long as you give appropriate credit to the original author(s) and the source, provide a link to the Creative Commons licence, and indicate if changes were made. The images or other third party material in this article are included in the article's Creative Commons licence, unless indicated otherwise in a credit line to the material. If material is not included in the article's Creative Commons licence and your intended use is not permitted by statutory regulation or exceeds the permitted use, you will need to obtain permission directly from the copyright holder. To view a copy of this licence, visit http://creativecommons.org/licenses/by/4.0/. The Creative Commons Public Domain Dedication waiver (http://creativecommons.org/publicdomain/zero/1.0/) applies to the data made available in this article, unless otherwise stated in a credit line to the data. 
addition, several groups demonstrated that TyG index could predict the incidence of type 2 diabetes $[18,19]$ and cardiovascular disease [20]. Thus, we hypothesized that TyG index can predict the incidence of CRC. However, no previous studies have investigated this association. We conducted the investigation of association between TyG index and incident CRC in this retrospective study.

\section{Methods}

\section{Study participants and study design}

This was a retrospective sub-analysis of the ongoing cohort study named NAGALA (NAfld in the Gifu Area, Longitudinal Analysis) study, which is a medical checkup program and a cohort investigation that has been ongoing at Asahi University Hospital (Gifu, Japan). The impact of TyG index on the risk of incident CRC was investigated in this NAGALA study. This investigation has been ongoing and aims to detect chronic diseases and their risk factors, and to promote public health. The detail of NAGALA study and medical examination programs were expressed in our previous study [21]. We recruited the participants in this medical examination program from 2003 to 2016. The exclusion criteria were follows: the participants whose data, including smoking status and alcohol consumption, were missed. The informed consent to participate was provided from all patients in this sub-analysis of NAGALA study. The present study was approved by each hospital's Ethics Committee.

\section{Data collection and measurements}

In a standardized self-administered questionnaire, the medical background and the data of alcohol consumption, smoking status and physical activity were taken from all of the participants [21]. In the questionnaire, we asked about the type and amount of alcohol consumption per week during the prior month, then we estimated the mean ethanol intake per week. The participants were categorized into the following four groups: no or minimal alcohol consumer, $<40 \mathrm{~g} /$ week; light, $40-140 \mathrm{~g} /$ week; moderate, $140-280 \mathrm{~g} /$ week; or heavy alcohol consumer, $>280 \mathrm{~g} /$ week [22]. In addition, the participants were categorized into the following three groups by smoking status: non-, ex-, or current smoker. Furthermore, we also asked participants' recreational activities and sports activities by questionnaire. We defined regular exercisers as individuals regularly over one time per week playing any type of sports [23]. Lastly, TyG index was calculated as ln [fasting triglycerides $(\mathrm{mg} / \mathrm{dL}) \times$ fasting plasma glucose $(\mathrm{mg} / \mathrm{dL}) / 2]$ [16]

\section{Identification of cases of colorectal cancer}

We performed fecal occult blood test in this health checkup program. When the fecal occult test was positive and the presence of CRC was suspected, the staffs informed and recommended participants to receive further examinations such as lower gastrointestinal endoscopy. We gathered the medical information regarding colorectal cancers by a standardized letter from a hospital where a participant receives further examinations.

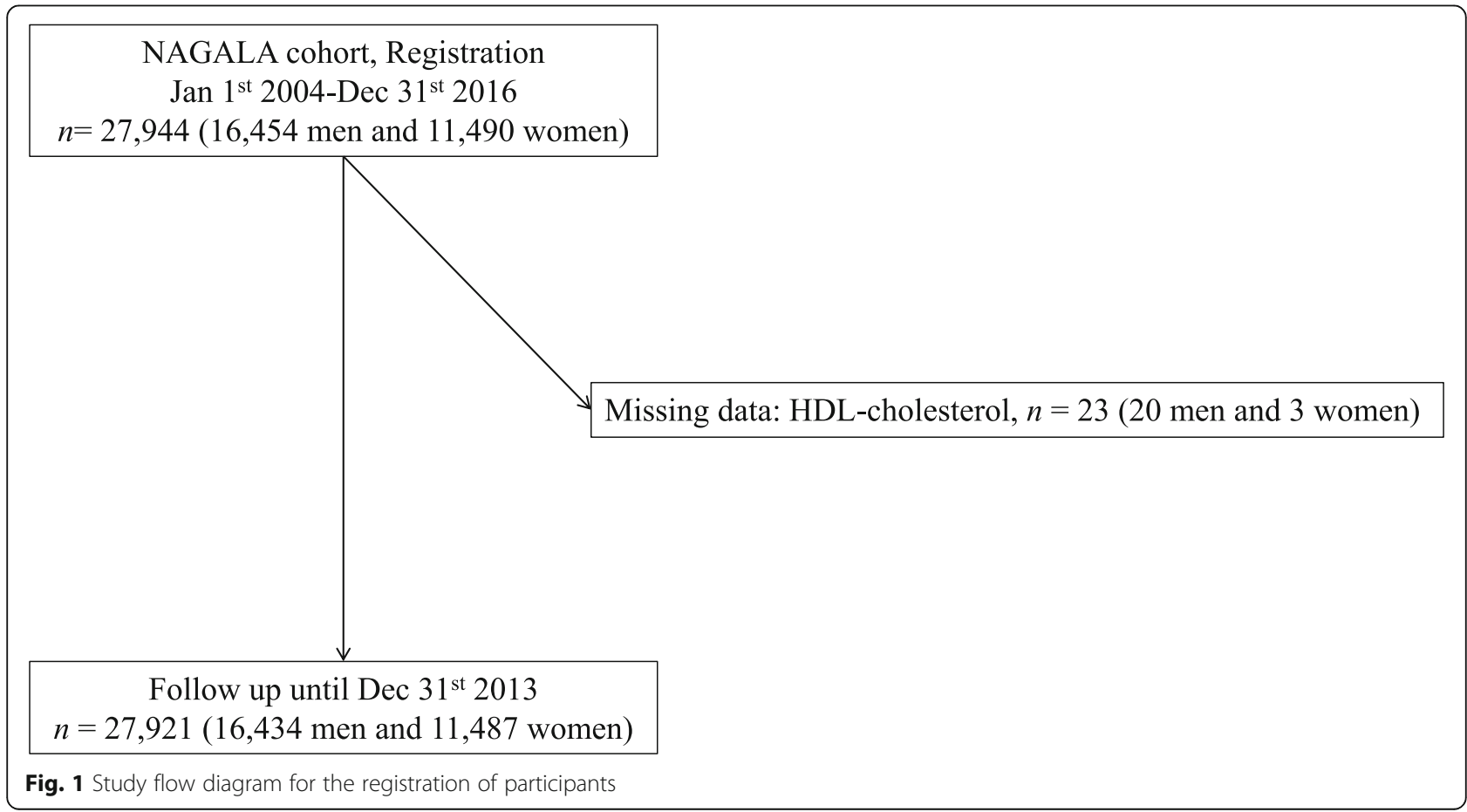


Besides, we included participants who received further examinations for reasons other than occult blood test and were diagnosed as colorectal cancer. The gastroenterologist checked the gathered information and defined them as colorectal cancer. From Jan 1st 2004, we adopted the standardized letter. Then, we set the study period as Jan 1st 2004 to Dec 31st 2016. The primary endpoint in this study was set as incident CRC. In this study, we defined the day when participants were suggested as cancer at the health checkup center as the onset day if participants were diagnosed as CRC.

\section{Statistical analysis}

We performed the following analyses with the JMP software ver. 13.0 (SAS, Cary, NC, USA). A $p$-value was considered to indicate a significant when it was less than 0.05. We expressed values as mean (SD) or median (interquartile) for continuous variables and number (\%) for categorial variables. The baseline characteristics of participants who developed CRC and those who did not

Table 1 Clinical characteristics of participants

\begin{tabular}{|c|c|}
\hline & Total $(n=27,921)$ \\
\hline Sex, men/women & $16,434 / 11,487$ \\
\hline Age, yrs & $45.7(10.1)$ \\
\hline $\mathrm{BMI}, \mathrm{kg} / \mathrm{m}^{2}$ & $22.6(3.3)$ \\
\hline$W C, \mathrm{~cm}$ & $78.1(9.6)$ \\
\hline Ex-smoker & $6185(22.2)$ \\
\hline Current-smoker & $6921(24.9)$ \\
\hline Regular exerciser & $4984(18.0)$ \\
\hline Light alcohol consumer & $2984(10.8)$ \\
\hline Moderate alcohol consumer & $2577(9.3)$ \\
\hline Heavy alcohol consumer & $2198(8.0)$ \\
\hline Fasting plasma glucose, $\mathrm{mmol} / \mathrm{L}$ & $5.3(0.7)$ \\
\hline $\mathrm{HbA} 1 \mathrm{c}, \%$ & $5.3(0.6)$ \\
\hline $\mathrm{HbA} 1 \mathrm{c}, \mathrm{mmol} / \mathrm{mol}$ & $34.6(5.4)$ \\
\hline Triglycerides, mmol/L & $1.0(0.9)$ \\
\hline Total cholesterol, mmol/L & $5.2(0.9)$ \\
\hline $\mathrm{HDL}$ cholesterol, mmol/L & $1.4(0.4)$ \\
\hline AST, IU/L & $19.5(9.7)$ \\
\hline$A L T, I U / L$ & $21.5(15.2)$ \\
\hline GGT, IU/L & $23.6(25.3)$ \\
\hline $\mathrm{SBP}, \mathrm{mmHg}$ & $117.7(16.4)$ \\
\hline $\mathrm{DBP}, \mathrm{mmHg}$ & $73.6(11.2)$ \\
\hline Creatinine, Creatinine, $\mu \mathrm{mol} / \mathrm{L}$ & $73.0(22.8)$ \\
\hline TyG index & $8.2(0.7)$ \\
\hline
\end{tabular}

ALT alanine transaminase, $A S T$ aspartate transaminase, $B M I$ body mass index, DBP diastolic blood pressure, GGT Y-glutamyltransferase, HbA1c hemoglobin A1c, HDL high density lipoprotein, SBP systolic blood pressure, TyG index triglyceride-glucose index, WC waist circumference

Data are mean (SD) or number were investigated. The $p$ values were calculated uby oneway analysis of variance (ANOVA) for continuous variables and chi-squared test for categorical variables, respectively.

Cox proportional hazards models were used to estimate hazard ratio (HR) and 95\% confidence interval (CI) for incident CRC. In Model 1, we unadjusted, in Model 2 , we adjusted for sex and age, and, in Model 3, we adjusted for Model 2 and body mass index, smoking status, alcohol consumption, exercise habit, systolic blood pressure and serum creatinine.

Additionally, the covariate-adjusted receiver operating characteristic (ROC) curve calculated the area under the curve (AUC) and cut-off value of TyG index for the incidence of CRC, and the AUC of TyG index was

Table 2 Clinical characteristics of participants

\begin{tabular}{|c|c|c|c|}
\hline & $\begin{array}{l}\text { CRC }(-) \\
(n=27,805)\end{array}$ & $\begin{array}{l}\text { CRC (+) } \\
(n=116)\end{array}$ & $P$-value \\
\hline Sex, men/women & $16,353 / 11,452$ & $81 / 35$ & 0.014 \\
\hline Age, yrs & $45.6(10.1)$ & $51.1(9.3)$ & $<0.001$ \\
\hline $\mathrm{BMI}, \mathrm{kg} / \mathrm{m}^{2}$ & $22.6(3.3)$ & $23.1(3.5)$ & 0.084 \\
\hline$W C, \mathrm{~cm}$ & $78.0(9.6)$ & $80.5(8.9)$ & 0.006 \\
\hline Smoking status & - & - & 0.003 \\
\hline Non-smoker & $14,772(53.0)$ & $43(37.1)$ & - \\
\hline Ex-smoker & $6150(22.1)$ & $35(30.2)$ & - \\
\hline Current smoker & $6883(24.8)$ & $38(32.8)$ & - \\
\hline Regular exerciser & $4964(18.0)$ & $20(17.5)$ & 0.905 \\
\hline Alcohol consumption & - & - & $<0.001$ \\
\hline Light alcohol consumer & $4682(17.0)$ & $23(20.0)$ & - \\
\hline Moderate alcohol consumer & $2560(9.3)$ & $17(14.8)$ & - \\
\hline Heavy alcohol consumer & $2177(7.9)$ & $21(18.3)$ & - \\
\hline Fasting plasma glucose, $\mathrm{mmol} / \mathrm{L}$ & $5.4(1.0)$ & $5.7(1.4)$ & 0.004 \\
\hline $\mathrm{HbA} 1 \mathrm{c}, \%$ & $5.3(0.6)$ & $5.4(0.8)$ & 0.042 \\
\hline $\mathrm{HbA} 1 \mathrm{c}, \mathrm{mmol} / \mathrm{mol}$ & $34.6(6.8)$ & $35.9(8.2)$ & 0.042 \\
\hline Triglycerides, mmol/L & $1.0(0.9)$ & $1.3(1.0)$ & 0.002 \\
\hline Total cholesterol, mmol/L & $5.2(0.9)$ & $5.4(0.9)$ & 0.011 \\
\hline HDL cholesterol, mmol/L & $1.4(0.4)$ & $1.3(0.4)$ & 0.012 \\
\hline Creatinine, $\mu \mathrm{mol} / \mathrm{L}$ & $73.0(22.8)$ & $76.7(16.1)$ & 0.039 \\
\hline AST, IU/L & $19.5(9.7)$ & $19.1(7.6)$ & 0.664 \\
\hline ALT, IU/L & $21.5(15.2)$ & $20.9(9.2)$ & 0.689 \\
\hline GGT, IU/L & $23.6(25.2)$ & $28.1(32.3)$ & 0.053 \\
\hline $\mathrm{SBP}, \mathrm{mmHg}$ & $117.7(16.4)$ & $121.2(17.1)$ & 0.018 \\
\hline $\mathrm{DBP}, \mathrm{mmHg}$ & $73.6(11.2)$ & $76.7(11.0)$ & 0.004 \\
\hline TyG index & $8.2(0.7)$ & $8.4(0.7)$ & $<0.001$ \\
\hline
\end{tabular}

$A L T$ alanine transaminase, $A S T$ aspartate transaminase, $B M I$ body mass index, $C R C$ colorectal cancer, DBP diastolic blood pressure, $G G T$ Y-glutamyltransferase, $H b A 1 c$ hemoglobin A1C, HDL high density lipoprotein, SBP systolic blood pressure, TyG index triglyceride-glucose index, WC: waist circumference Data are mean (SD) or number 
compared with those of BMI, brinkman index, alcohol consumption, total cholesterol, and triglycerides.

\section{Results}

From Jan 1st in 2004 to Dec 31st in 2016, 27,944 participants (16,454 men and 11,490 women) were registered in NAGALA cohort. After excluding those who met exclusion criteria, 27,921 participants (16,434 men and 11, 487 women) were entered (Fig. 1). The baseline characteristics of the participants are shown in Table 1. Mean ( \pm standard deviation) age of participants was $45.7 \pm$ 10.1 years old and BMI was $22.6 \pm 3.3 \mathrm{~kg} / \mathrm{m}^{2}$.

Participants who developed CRC were older than those who did not $(51.1 \pm 9.3$ vs $45.6 \pm 10.1$ years, $p<$ 0.001). Next, alcohol consumption of participants who developed CRC was greater than that of those who did not. In the metabolic status, fasting plasma glucose, hemoglobin A1c, triglycerides, total cholesterol, serum creatinine, and systolic and diastolic blood pressure of participants who developed CRC were higher than those of participants who did not (Table 2).

One hundred sixteen participants were diagnosed as CRC during the median 4.4-year follow-up. The cumulative incidence rate of CRC was $0.4 \%$. In Cox proportional hazard model, the HRs of TyG index were 1.65 $(95 \%$ CI $1.29-2.13, p<0.001)$ in Model 1, 1.41 (1.051.89, $p=0.021)$ in Model 2 and $1.36(1.00-1.86, p=$ 0.049 ) in Model 3 (Table 3 qaxzdf). Moreover, the cutoff value of TyG index for incident CRC was 8.272 in the covariate-adjusted ROC curve analysis (AUC 0.687 $(95 \% \mathrm{CI}, \quad 0.637-0.737, \quad$ sensitivity $=0.620$, specificity $=$ $0.668, p<0.001)$ ). Additionally, we also calculated AUC of BMI (0.547, 95\% CI: $0.498-0.602, p<0.001$, vs. TyG index), that of brinkman index (0.605, 95\% CI: $0.551-$ $0.654, p<0.001$, vs. TyG index), that of alcohol consumption $(0.623,95 \%$ CI: $0.571-0.676, p<0.001$, vs. TyG index), that of TC $(0.563,95 \% \mathrm{CI}: 0.515-0.616, p<$ 0.001 , vs. TyG index), and that of TG $(0.608,95 \%$ CI: $0.560-0.658, p<0.001$, vs. TyG index), respectively (Fig. 2). TyG index had a significantly higher AUC for the development of CRC than the other risk factors.

\section{Discussion}

In this retrospective cohort study of over 27,000 Japanese participants, we investigated the affect of TyG index on incidence of CRC and, for the first time, demonstrated that TyG index could predict incidence of CRC. TyG index, calculated with fasting triglycerides and plasma glucose, was originally proposed as a biomarker of insulin resistance [16, 17], and some following studies demonstrated TyG index could predict the incidence of type 2 diabetes $[18,19]$ and cardiovascular disease [20]. In addition, we showed that the value of TyG index of 8.272 was a cut-off value for incident of CRC. In fact, we compared area under the curve (AUC) of TyG index with that of the known risk factors of the CRC: BMI, smoking, alcohol consumption [24], TC, and TG [25]. Then, TyG index was superior to other markers.

Several human studies previously reported the association between insulin resistance and risk of colorectal cancer [13-15]. Similarly, several basic researches revealed that insulin resistance was reported to be associated with hyperinsulinemia $[7,8]$, increased levels of IGF $[9,10]$, and alterations in NF-kB [11] and PPAR $\gamma$

Table 3 Cox proportional hazards for incident colorectal cancer

\begin{tabular}{|c|c|c|c|c|c|c|}
\hline & \multicolumn{2}{|l|}{ Model 1} & \multicolumn{2}{|l|}{ Model 2} & \multicolumn{2}{|l|}{ Model 3} \\
\hline & HR $(95 \% \mathrm{Cl})$ & $p$-value & HR $(95 \% \mathrm{Cl})$ & $p$-value & HR (95\% Cl) & $p$-value \\
\hline Men & - & - & $1.09(0.71-1.70)$ & 0.712 & $1.01(0.59-1.84)$ & 0.975 \\
\hline Age, years & - & - & 1.07 (1.05-1.09) & $<0.001$ & 1.07 (1.04-1.09) & $<0.001$ \\
\hline $\mathrm{BMI}, \mathrm{kg} / \mathrm{m}^{2}$ & - & - & - & - & $0.99(0.93-1.07)$ & 0.912 \\
\hline Ex-smoker & - & - & - & - & $1.48(0.84-2.61)$ & 0.176 \\
\hline Current smoker & - & - & - & - & $1.55(0.87-2.75)$ & 0.117 \\
\hline Light alcohol consumer & - & - & - & - & $1.32(0.77-2.24)$ & 0.298 \\
\hline Moderate alcohol consumer & - & - & - & - & $1.55(0.87-2.75)$ & 0.137 \\
\hline Heavy alcohol consumer & - & - & - & - & $2.02(1.14-3.57)$ & 0.016 \\
\hline Regular exerciser & - & - & - & - & $0.79(0.46-1.29)$ & 0.360 \\
\hline Systolic blood pressure, mmHg & - & - & - & - & $0.99(0.99-1.01)$ & 0.987 \\
\hline Creatinine, $\mu \mathrm{mol} / \mathrm{L}$ & - & - & - & - & $0.85(0.25-2.89)$ & 0.794 \\
\hline TyG index & $1.65(1.29-2.13)$ & $<0.001$ & $1.41(1.05-1.89)$ & 0.021 & $1.38(1.00-1.91)$ & 0.049 \\
\hline
\end{tabular}

BMI body mass index, TyG index triglyceride-glucose index. Exercise was defined as nonregular exerciser (0) or regular exerciser (1), smoking status was defined as nonsmoker (0), ex-smoker (1) or current smoker (2), and alcohol consumption was defined as no or minimal alcohol consumer (0), light alcohol consumer (1), moderate alcohol consumer (2) and heavy alcohol consumer (3). Model 1 was unadjusted. Model 2 was adjusted for sex and age. Model 3 was adjusted for sex, age, body mass index, smoking status, alcohol consumption, exercise, systolic blood pressure and serum creatinine 


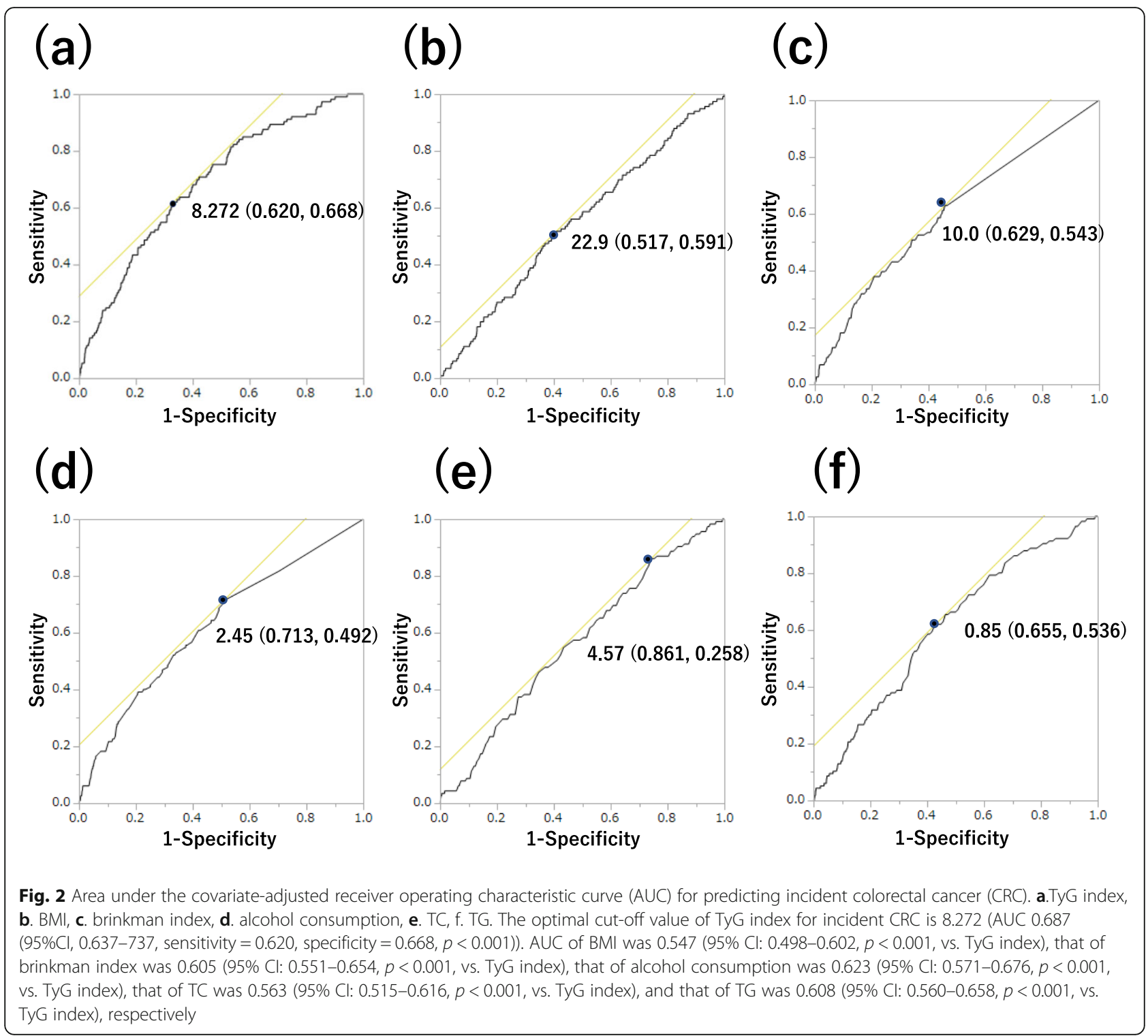

signaling [12], which may play a key role in the pathogenesis of CRC.

Insulin resistance induces hyperinsulinemia, which activates PI3K/Akt/mTOR/S6K signaling pathway in cancer [26]. Additionally, elevated serum TG, a component of the TyG index, activates Akt signaling pathway through G protein-coupled receptor [27]. In fact, the gene expression of the PI3K/Akt/mTOR signaling axis in human colorectal cancer are significantly overexpressed compared to normal colonic tissues [28]. Moreover, some recent studies reported that insulin promotes colon cancer progression by upregulation of acyl coenzyme A: cholesterol acyltransferase1 [29], and increases the expression of vascular cell adhesion molecule- 1 in intestinal tumor endothelial cells and produces proinflammatory state which promotes tumorigenesis [30].
Taken together, hyperinsulinemia caused by insulin resistance may contribute to the growth and progression of colorectal cancer.

Insulin resistance is related with increased IGF-1 levels $[9,10]$. IGF-1 activates IGF-1 receptor, which regulate cell proliferation, survival, and angiogenesis [31]. IGF-1 promotes to product vascular endothelial growth factor, which supports tumor growth [32]. In fact, the expression of IGF-1 and IGF-1 receptor increases with tumor size in colorectal cancer in a human study [33]. In addition, hyperglycemia enhances the cellular sensitivity to IGF-I, including increased cell proliferation and migration [34].

Hyperglycemia is reported to induce an increase in intranuclear NF- $\mathrm{kB}$ in human subjects [35]. NF- $\mathrm{kB}$ regulates a number of genes included in the process of cell 
proliferation, neoplasia, and metastasis. Moreover, two target genes for NF- $\mathrm{kB}$ such as cyclin D1 and cMyc take an important part in cell growth and proliferation [36]. In the carcinogenic process of CRC, the NF- $\mathrm{kB}$ signaling pathway is an important complex pathway. The changes of gene expression in signaling pathway by insulin resistance downregulated the genes with a positive role of immune response and upregulated the genes of proinflammatory, which induced potent immune response and inflammation [37].

Sarraf, et al. [38] demonstrated that the growth and differentiation of colon cancer cells can be modulated through PPAR $\gamma$, and since then, many groups have reported the association between PPAR $\gamma$ signaling and CRC [39-41]. Kubota, et al. [42] demonstrated the association between PPAR $\gamma$ and insulin resistance in adipocyte. In addition, colorectal tumor is developed by the activation of PPARY [43].

In addition, both serum plasma glucose and triglycerides levels are related with risk of CRC in human subjects $[2,6]$. TyG index is composed of levels of triglyceride and glucose, and it is expected that TyG index is more useful risk marker of CRC.

Our study also has some limitations. We did not perform colonoscopy to all participants. In addition, the proportion of the participants who received further examinations was approximately only $50 \%$ out of the participants whose fecal occult tests were positive. Therefore, there was a possibility that the number of incident CRC was underestimated. However, CRC incidence in this study was $0.4 \%$ and that available for all generations in Japan is $0.2 \%$ [44]. Therefore, underestimation of incident CRC might be smaller than expected. Lastly, in the present study, only the TyG index at the initial visit was included in the analysis, and we did not take into account factors of improvement and deterioration during the course of follow-up.

\section{Conclusions}

In conclusion, TyG index is a useful and accessible tool for predicting incident CRC. For early detection of CRC, we should encourage people with high TyG index, the cut-off value of which was 8.272 in our study, to undergo screening for CRC.

\footnotetext{
Abbreviations

ANOVA: Analysis of variance; AUC: Area under the curve; $\mathrm{Cl}$ : Confidence interval; CRC: Colorectal cancer; HR: Hazard ratio; IGF: Insulin-like growth factors; NF: Necrosis factor; PPARY: Peroxisome proliferator-activated receptor gamma; ROC: Receiver operating characteristic; TyG index: Triglycerideglucose index
}

\section{Acknowledgments}

We thank all of the staff members in the medical health checkup center at Asahi University Hospital.

\section{Authors' contributions}

T.O. contributed to the data research and analyses and wrote the manuscript. Y.H. originated and designed the study, analyzed the data and reviewed the manuscript for intellectual content. M.H. contributed to data research and the manuscript organization and reviewed and edited the manuscript. A.O. and T.K. contributed to originate the study, data research and contributed to the discussion. M.F. analyzed the data and reviewed and edited the manuscript. H.M. is the guarantor of this work and, as such, had full access to all of the data in the study and takes responsibility for the integrity of the data and the accuracy of the data analysis. All authors were involved in the writing of the manuscript and approved the manuscript's final version.

\section{Funding}

None.

\section{Availability of data and materials}

The datasets used and analysed during the current study available from the corresponding author on reasonable request.

\section{Ethics approval and consent to participate}

All patients in this sub-analysis of NAGALA study provided their informed consent to participate. The present study was approved by Asahi University hospital's Ethics Committee. The consent we obtained from study participants was written.

\section{Consent for publication}

Not applicable.

\section{Competing interests}

Y. Hashimoto received grants from Japan Society for the Promotion of Science, Asahi Kasei Corporation, MSD K.K., and Fuji Foundation for Protein Research, outside the submitted work. M. Fukui received grants from Japan Society for the Promotion of Science, AstraZeneca plc, Astellas Pharma Inc., Nippon Boehringer Ingelheim Co., Ltd., Daiichi Sankyo Co., Ltd., Eli Lilly Japan K.K., Kyowa Hakko Kirin Co. Ltd., Kissei Pharmaceutical Co., Ltd., MSD K.K., Mitsubishi Tanabe Pharma Corp., Novo Nordisk Pharma Ltd., Sanwa Kagaku Kenkyusho Co., Ltd., Sanofi K.K., Ono Pharmaceutical Co., Ltd., and Takeda Pharmaceutical Co., Ltd., outside the submitted work. The sponsors were not involved in the study design; in the collection, analysis, interpretation of data; in the writing of this manuscript; or in the decision to submit the article for publication. The authors, their immediate families, and any research foundations with which they are affiliated have not received any financial payments or other benefits from any commercial entity related to the subject of this article. The authors declare that although they are affiliated with a department that is supported financially by pharmaceutical company, the authors received no current funding for this study, and this does not alter their adherence to all the journal policies on sharing data and materials. The other authors have nothing to disclose.

\section{Author details}

${ }^{1}$ Department of Endocrinology and Metabolism, Kyoto Prefectural University of Medicine, Graduate School of Medical Science, 465, Kajii-cho,

Kawaramachi-Hirokoji, Kamigyo-ku, Kyoto 602-8566, Japan. ${ }^{2}$ Department of Gastroenterology, Asahi University Hospital, Gifu, Japan.

Received: 6 March 2020 Accepted: 22 June 2020

Published online: 24 July 2020

\section{References}

1. Cancer sheets. World Heal Organ 2018. http://www.who.int/news-room/ fact-sheets/detail/cancer (Accessed 20 Dec 2018).

2. Ahmed RL, Schmitz KH, Anderson KE, Rosamond WD, Folsom AR. The metabolic syndrome and risk of incident colorectal cancer. Cancer. 2006; 107:28-36.

3. Russo A, Autelitano M, Bisanti L. Metabolic syndrome and cancer risk. Eur J Cancer. 2008;44:293-7.

4. Stocks T, Lukanova A, Johansson M, et al. Components of the metabolic syndrome and colorectal cancer risk; a prospective study. Int J Obes. 2008; 32:304-14. 
5. Inoue M, Noda M, Kurahashi N, et al. Impact of metabolic factors on subsequent cancer risk: results from a large-scale population-based cohort study in Japan. Eur J Cancer Prev. 2009;18:240-7.

6. Aleksandrova $\mathrm{K}$, Boeing $\mathrm{H}$, Jenab $\mathrm{M}$, et al. Metabolic syndrome and risks of colon and Rectal cancer: the European prospective investigation into cancer and nutrition study. Cancer Prev Res. 2011:4:1873-83.

7. McKeown-Eyssen G. Epidemiology of colorectal cancer revisited: are serum triglycerides and/or plasma glucose associated with risk? Cancer Epidemiol Biomark Prev. 1994;3:687-95.

8. Palmqvist $R$, Hallmans $G$, Rinaldi $S$, et al. Plasma insulin-like growth factor 1 , insulin-like growth factor binding protein 3, and risk of colorectal cancer: a prospective study in northern Sweden. Gut. 2002;50:642-6.

9. Giovannucci E. Insulin, insulin-like growth factors and colon cancer: a review of the evidence. J Nutr. 2001;131:3109-20.

10. Friedrich $\mathrm{N}$, Thuesen $\mathrm{B}$, Jorgensen $\mathrm{T}$, et al. The association between IGF-I and insulin resistance: a general population study in Danish adults. Diabetes Care. 2012;35:768-73.

11. Saldeen J, Welsh N. p38 MAPK inhibits JNK2 and mediates cytokineactivated iNOS induction and apoptosis independently of NF-KB translocation in insulin-producing cells. Eur Cytokine Netw. 2004;15:47-52.

12. Bogazzi F, Ultimieri F, Raggi F, et al. PPARgamma inhibits GH synthesis and secretion and increases apoptosis of pituitary GH-secreting adenomas. Eur J Endocrinol. 2004;150:863-75.

13. Schoen RE, Tangen CM, Kuller LH, et al. Increased blood glucose and insulin, body size, and incident colorectal cancer. J Natl Cancer Inst. 1999:91:1147-54.

14. Yamamoto S, Nakagawa T, Matsushita Y, et al. Visceral fat area and markers of insulin resistance in relation to colorectal neoplasia. Diabetes Care. 2010; 33:184-9.

15. Limburg PJ, Stolzenberg-Solomon RZ, Vierkant RA, et al. Insulin, glucose, insulin resistance, and incident colorectal cancer in male smokers. Clin Gastroenterol Hepatol. 2006;4:1514-21.

16. Simental-Mendía LE, Rodríguez-Morán M, Guerrero-Romero F. The product of fasting glucose and triglycerides as surrogate for identifying insulin resistance in apparently healthy subjects. Metab Syndr Relat Disord. 2008;6: 299-304.

17. Du T, Yuan G, Zhang M, Zhou X, Sun X, Yu X. Clinical usefulness of lipid ratios, visceral adiposity indicators, and the triglycerides and glucose index as risk markers of insulin resistance. Cardiovasc Diabetol. 2014;13:146.

18. Navarro-González D, Sánchez-Iñigo L, Pastrana-Delgado J, FernándezMontero A, Martinez JA. Triglyceride-glucose index (TyG index) in comparison with fasting plasma glucose improved diabetes prediction in patients with normal fasting glucose: the vascular-metabolic CUN cohort. Prev Med (Baltim). 2016;86:99-105.

19. Low S, Chin Jonathon Khoo K, Irwan B, et al. The role of triglyceride glucose index in development of type 2 diabetes mellitus. Diabetes Res Clin Pract. 2018;143:43-9.

20. Sánchez-lñigo L, Navarro-González D, Fernández-Montero A, PastranaDelgado J, Martínez JA. The TyG index may predict the development of cardiovascular events. Eur J Clin Investig. 2016:46:189-97.

21. Hamaguchi M, Kojima T, Takeda N, et al. The metabolic syndrome as a predictor of nonalcoholic fatty liver disease. Ann Intern Med. 2005;143:722-8.

22. Hashimoto $Y$, Hamaguchi M, Kojima T, et al. Modest alcohol consumption reduces the incidence of fatty liver in men: a population-based large-scale cohort study. J Gastroenterol Hepatol. 2015;30:546-52.

23. Ryu S, Chang Y, Kim D-I, Kim WS, Suh B-S. Glutamyltransferase as a predictor of chronic kidney disease in nonhypertensive and nondiabetic Korean men. Clin Chem. 2006;53:71-7.

24. Wulaningsih W, Garmo H, Holmberg L, et al. Serum lipids and the risk of gastrointestinal malignancies in the Swedish AMORIS study. J Cancer Epidemiol. 2012;2012:792034

25. Colditz GA, Atwood KA, Emmons K, et al. Harvard report on cancer prevention volume 4: Harvard cancer risk index. Risk index working group, Harvard center for cancer prevention. Cancer Causes Control. 2000;11:477-88.

26. Khan KH, Yap TA, Yan L, Cunningham D. Targeting the PI3K-AKT-mTOR signaling network in cancer. Chin J Cancer. 2013;32:253-65.

27. Sekine Y, Koike H, Nakano T, Nakajima K, Suzuki K. Remnant lipoproteins stimulate proliferation and activate MAPK and Akt signaling pathways via G protein-coupled receptor in PC-3 prostate cancer cells. Clin Chim Acta. 2007;383:78-84.
28. Johnson SM, Gulhati P, Rampy BA, et al. Novel expression patterns of PI3K Akt/mTOR signaling pathway components in colorectal cancer. J Am Coll Surg. 2010;210:767-78

29. Chen $X$, Liang $H$, Song $Q, X u X$, Cao D. Insulin promotes progression of colon cancer by upregulation of ACAT1. Lipids Health Dis. 2018;17:122.

30. Wang $X$, Häring M-F, Rathjen $T$, et al. Insulin resistance in vascular endothelial cells promotes intestinal tumour formation. Oncogene. 2017;36: 4987-96.

31. Aaronson SA. Growth factors and cancer. Science. 1991;254:1146-53.

32. Warren RS, Yuan H, Matli MR, Ferrara N, Donner DB. Induction of vascular endothelial growth factor by insulin-like growth factor 1 in colorectal carcinoma. J Biol Chem. 1996;271:29483-8.

33. Shiratsuchi I, Akagi Y, Kawahara A, et al. Expression of IGF-1 and IGF-1R and their relation to clinicopathological factors in colorectal cancer. Anticancer Res. 2011;31:2541-5.

34. Maile LA, Capps BE, Ling Y, Xi G, Clemmons DR. Hyperglycemia alters the responsiveness of smooth muscle cells to insulin-like growth factor-I. Endocrinology. 2007;148:2435-43.

35. Aljada A, Friedman J, Ghanim H, Mohanty P, Hofmeyer D, Chaudhuri A, et al. Glucose ingestion induces an increase in intranuclear nuclear factor $\mathrm{KB}$, a fall in cellular inhibitor $\mathrm{KB}$, and an increase in tumor necrosis factor a messenger RNA by mononuclear cells in healthy human subjects. Metabolism. 2006;55:1177-85.

36. Chen C, Edelstein LC, Gélinas C. The Rel/NF-kappaB family directly activates expression of the apoptosis inhibitor BCl-x (L). Mol Cell Biol. 2000;20:2687-95.

37. Slattery ML, Mullany LE, Sakoda L, et al. The NF-KB signalling pathway in colorectal cancer: associations between dysregulated gene and miRNA expression. J Cancer Res Clin Oncol. 2018;144:269-83.

38. Sarraf $P$, Mueller $E$, Jones $D$, et al. Differentiation and reversal of malignant changes in colon cancer through PPARy. Nat Med. 1998:4:1046-52.

39. Sarraf $P$, Mueller $E$, Smith WM, et al. Loss-of-function mutations in PPAR gamma associated with human colon cancer. Mol Cell. 1999:3:799-804.

40. Gong Z, Xie D, Deng Z, et al. The PPAR Pro12Ala polymorphism and risk for incident sporadic colorectal adenomas. Carcinogenesis. 2004;26:579-85.

41. Shimada T, Kojima K, Yoshiura K, Hiraishi H, Terano A. Characteristics of the peroxisome proliferator activated receptor gamma (PPARgamma) ligand induced apoptosis in colon cancer cells. Gut. 2002:50:658-64.

42. Kubota N, Terauchi Y, Miki H, et al. PPAR gamma mediates high-fat dietinduced adipocyte hypertrophy and insulin resistance. Mol Cell. 1999;4:597609.

43. Lefebvre AM, Chen I, Desreumaux $\mathrm{P}$, et al. Activation of the peroxisome proliferator-activated receptor gamma promotes the development of colon tumors in C57BL/6J-APCMin/+ mice. Nat Med. 1998;4:1053-7.

44. Latest cancer statistics. Natl Cancer Cent Japan 2017. https://ganjoho.jp/ reg_stat/statistics/stat/summary.html (Accessed 20 Dec 2018).

\section{Publisher's Note}

Springer Nature remains neutral with regard to jurisdictional claims in published maps and institutional affiliations.

Ready to submit your research? Choose BMC and benefit from:

- fast, convenient online submission

- thorough peer review by experienced researchers in your field

- rapid publication on acceptance

- support for research data, including large and complex data types

- gold Open Access which fosters wider collaboration and increased citations

- maximum visibility for your research: over $100 \mathrm{M}$ website views per year

At BMC, research is always in progress.

Learn more biomedcentral.com/submission 